\title{
Competitive intelligence in business: Latin America
}

\author{
Marié-Luce Muller \\ Managing Director and CI Analyst \\ IBIS Business and Information Services \\ mlm@ibis.co.za \\ www.ibis.co.za
}

\section{Introduction}

This year's series of columns on competitive intelligence (CI) kicked off by assessing the status quo of CI practices globally in various countries. In reaction to the first article of 2007, a Latin American colleague, Adrian Alvarez, pointed out that Latin America was overlooked and that CI is, indeed, a legitimate business activity in countries such as Argentina, Brazil and Mexico. That led to the decision to dedicate the second article of 2007 to the CI practices in Latin America with brief comparisons to the CI practices in South Africa.

$\mathrm{CI}$ is not an activity limited to a few countries or companies in certain industries; it is a world-wide phenomenon. Most of the Fortune 500 companies use CI extensively. Literature shows some countries such as France, Japan, Sweden and the USA to be more advanced in their embracement of CI as a means to enhance competitiveness (Viviers and Muller 2004). In these countries, $\mathrm{CI}$ is a recognized business discipline and has become a major source to achieve competitive advantage. They are also developed in terms of the role government plays in supporting CI and business activities.

\section{Changing competitive landscape}

Having studied the fairly limited literature available on CI in Latin America, the deduction could be made that it is still in a growing phase displaying the typical characteristics of an emerging discipline, much where South Africa was in the late 1990s and early 2000s, including a lack of awareness of its benefits, a lack of the right information and inadequate formal training programmes at a higher education level.

The case for CI is strong however. Latin America seems to be struggling with the same competitiveness issues that South Africa has, including a liberalizing economy, a changing business scene and heightened competition. Both South Africa and Latin America could also be seen as being geographically distant from some of the leading global markets.

In terms of competitiveness, it seems that the governments of South Africa and Latin America (Venezuela, Argentina, Brazil and Mexico) both lag behind their economy. They fail to perform in various areas, for example budget deficits, policies, debt, taxes, bureaucracy and the creation of a business environment conducive to foreign direct investment (World Competitiveness Yearbook, 2006). According to the IMD, which compiles the World Competitiveness Yearbook, these governments hinder the overall competitiveness 
of their countries. Poor regulations governing land ownership and zoning, as well as the direct regulation of prices or products, inhibit competition by limiting the entry of new players, discouraging innovation among existing ones and restricting the scale of businesses. Bureaucratic practices further dampen competitiveness and hinder companies in the promotion of business.

This is affirmed in a research study published by McKinsey in May 2007 (Farrell and Remes 2007) who states that Latin America's economic performance continues to disappoint. Besides government, some of the factors hindering economic growth and competitiveness that they mention are inadequate GDP growth, low productivity and weak performance in the services sector.

As in South Africa, liberalizing economies inevitably result in new entrants, heightened competition and a changing business culture (Tendençias 2000). In Latin America, multinational companies, for example, had a significant impact on the competitive intensity of the local retail sector.

\section{Case for CI in Latin America}

Akin to South Africa, Latin America's competitive landscape is being reshaped and, with that, the need for CI as a means to enhance competitiveness is gaining ground. It does not mean that CI was a totally unknown practice - there was just no formalized structured approach in assessing the environment. CI as a business tool has been utilized in countries such as Brazil and Mexico since the late 1990s (Global Intelligence Alliance 2005).

New business realities, however, have led to CI gaining ground as a legitimate competitiveness tool. Latin American economies have liberalized with assets worth billions of US\$ being transferred to foreign ownership. According to Rideg, Muller and Price (2004), this is an indicator of the region's new business reality. From a foreign company or investor point of view, investment implies the need for preparatory work. This means that the viability has to be assessed through proper market intelligence. And with so little sound information being available publicly, the need for proper CI is highlighted. From a local company viewpoint, the intensifying competition and new business cultures that are introduced by foreign companies means that they no longer have the luxury of time to devise strategies and implement new business plans. The pace of business is still increasing and the need to take fast and accurate decisions is growing. Decisions based on 'gut feel' and rumours are no longer good enough (Rideg et al. 2004).

Yet, according to Rideg et al. (2004), few of the early investors who invested in the areas conducted proper viability studies to assess the opportunities and threats, leading to a situation where there was an excess supply of over-priced assets that lost substantial value. Other challenges that faced new entrants included the unpredictable tactics of local competitors, the prevalence of political bias and the uneven playing field. An expensive lesson learnt was that adequate time and resources must be allocated for CI.

\section{Planning and focus}

The need for CI is widely recognized although companies are varied in how they go about conducting CI. There is also an increased need for taking a more decisive stance towards CI. This change was brought about in reaction to the significant changes that have occurred in the Latin American business environment since the 1990s, including increased competition due to the entrance of foreign companies (Tendençias 2000). This competition has led to changes in the way business is done, the value of the right information and pressure on the interests of local companies. With increased competition comes the higher value attached to 
information and the increased need to improve knowledge, insights and strategies to remain competitive and in business.

$\mathrm{CI}$ is not about collecting all the information, but on focusing on the issues of highest importance to senior management (Herring 1998). It is also not just about focusing on competitors, but also on competitive elements such as customers, regulatory issues and products.

The recognition that knowledge of the business environment is imperative, has led to a need for better market research, including customer and competitor intelligence. These two areas were highlighted in a survey conducted by the Global Intelligence Alliance (2005) as receiving priority attention when determining key intelligence needs. The focus of current CI efforts on market and customer research means that it still has to grow in strategic stature such as competitive strategies, competitor intelligence and future trends.

\section{Information collection}

Rideg et al. (2004) has found that gathering information is one of the most challenging activity areas of CI in Latin America and that CI practitioners have had to devise unconventional and risky methods to do so. Reasons given for the difficulties in obtaining the right information include the lack of information sharing and the lack of public and published information. Few companies are public and therefore do not have to divulge corporate information. This includes financial data and basic corporate information. Furthermore, business information that is reported in the media is still limited and of little value.

However, the business media's coverage and quality of reporting is improving with the largest prevalent obstacle apparently being the Latin American closed business culture (Tendençias 2000). Little sharing of information takes place and there is also a high level of wariness to share information. It seems that due to the secrecy culture and the reluctance to share information, as well as the lack of reliable public sources of information, gathering tactics often include action that would be deemed unethical elsewhere such as misrepresentation, garbage hunting, snooping around and lying about reasons why information is required.

In an effort to gather information that is not easily accessible, companies are resorting to contracting specialists in the field of CI.

Adrian Alvarez (2006) conducted a survey on CI in Argentina in 2006 in which he found that information gathering is not given high priority but that analysis, interpretation and presentation of actionable intelligence ranks high among the CI activities.

\section{Analysis}

The analysis activity area of CI is arguably the most important and many practitioners believe that this is where 'true' intelligence is created through the conversion of information into actionable intelligence on which strategic and tactical decisions should be based (Gilad and Gilad 1985; Kahaner 1996).

The fact that in Latin America, analysis ranks as an activity area that is given higher priority than collecting information, is a positive finding. Often, it is the gathering of information that receives most time and attention, while the most important areas of analysis and interpretation rank lower in terms of the time spent on them. 
The focus of the analysis is also on issues of high strategic importance, which is equally positive. A Global Intelligence Alliance survey (2005) revealed that information collection and analysis are systematic CI activity areas in Latin American countries such as Brazil and Mexico.

Most of the information processing and analysis in countries such as Mexico and Brazil takes place in-house while the rest is outsourced (Global Intelligence Alliance 2005).

\section{Awareness and culture}

For companies to make optimal use of CI efforts, there needs to be an appropriate organizational awareness of CI. While decision makers should indicate or provide guidance as to what intelligence is required, information gathering should be a company-wide activity (Kahaner 1996). Without proper awareness and attitudes that favour both intelligence and information sharing, it is difficult to develop intelligence within a company.

$\mathrm{CI}$ is gaining ground and recognition as a strategic business tool that could enhance competitiveness. However, in countries such as Argentina, it is still primarily the larger companies that conduct CI, possibly due to economies of scale, a lack of knowledge and lower levels of development of CI (Alvarez 2006).

CI's growth, however, will depend on the creation of awareness of its benefits and a change in the way that companies deal with and view information. Other development areas that could prove to be hindrances in the way of CI growth include the general low ethical standards that prevail and the fear that such practices could lead to the harming of reputations. Alvarez (2006) expressed concern that, in view of the aforementioned, CI may mostly remain a part-time activity that is used when a need arises.

\section{Process and structure}

CI requires appropriate policies, procedures, and a formal (or informal) infrastructure so that employees may contribute effectively to the CI system as well as gain the benefits from the CI process. Ideally, CI should be a formalized activity conducted by a dedicated CI unit that is strategically placed in the company (Gilad and Gilad 1985).

The survey conducted by the Global Intelligence Alliance (2005) revealed that, although CI could not yet be described as a formalized activity in Latin America, certain activity areas of CI, such as information processing, are conducted in a systematic manner and that the CI responsibility often resides in the marketing departments of companies, addressing more operational information needs. Few people are dedicated to the CI function.

In Argentina, it has not yet been elevated to a top management capability with high strategic value and it is still predominantly a part-time activity that is focused more on data than intelligence (Alvarez 2006).

In terms of functions that utilize CI, the most important was seen to be strategic planning and business development and, to a slightly lesser extent, sales and marketing. Results from the Global Intelligence Alliance survey (2005), however, indicate that the use of internal sources of information in general could improve, especially against the background of the limited reliable and current public information available in the region. It is therefore not surprising to notice that information gathering is often outsourced while information processing and analysis are activities that are conducted in-house.

\section{CI research and consulting}


Only a few smaller companies make use of CI besides the foreign multi-nationals that are there (Alvarez 2006). With CI still in its infancy, for various reasons, it is not a profitable proposition at this stage.

CI is starting to emerge in Latin America, although limited research has been conducted and no dedicated university training courses are available. This will enhance the pool of information available for research purposes and might alter the way business and society deal with information.

As in Latin America, an assessment of the current CI programmes in South African learning institutions revealed limited formal academic programmes (Viviers and Muller 2004). Current programmes are mainly limited to short courses in basic CI principles. At present there are no CI courses presented at secondary schools in South Africa, and although some progress has been made in the development of courses, much still needs to be done. In Latin America, the situation is similar, but it is foreseen that, with the growing need for and engagement in CI activities, the market's need for more formalized training might lead to higher education institutions satisfying this need.

\section{Conclusion}

Having studied the literature available on CI practices in Latin America, a number of similarities to CI in South Africa were clear, including the challenges. CI practitioners in South Africa share with their Latin American counterparts the challenge of developing and using internal knowledge and the ability to accurately identify key intelligence needs while the delivery of focused strategic intelligence remains an ongoing quest (Global Intelligence Alliance 2005).

\section{References}

Alvarez, A. 2006. Argentina's needs assessment survey and its comparison to the UK. Buenos Aires: SCIP presentation.

Farrell, D. and Remes, J. 2007. Tapping Latin America's potential in services. McKinsey Global Institute. [Online]. Available WWW: http://www.mckinseyquarterly.com/article (Accessed May 2007).

Gilad B, and Gilad, T. 1985. A systems approach to business intelligence, Business Horizons 28(5):65-70.

Global Intelligence Alliance. 2005. Global study amongst large-scale companies. November. [Online]. Available: http://www.globalintelligence.com/news/news/latest/november92005/.

Herring, J. 1998. What is intelligence analysis? Competitive Intelligence Magazine 1(2):1316.

Kahaner, L. 1996. Competitive intelligence. How to gather, analyse and use information to move your business to the top. 1 st ed. New York: Simon \& Schuster.

Rideg, T., Muller, G.C. and Price, J. 2004. Competitive intelligence in Latin America. Tendencias InfoAmericas.

Tendençias. 2000. Regional trends: competitive intelligence in Latin America. April/May InfoAmericas. [Online]. Available: www.infoamericas.com. 
Viviers, W. and Muller, M-L. 2004. The evolution of competitive intelligence in South Africa: Early 1980s-2003. Journal of Competitive Intelligence and Management 2(2).

\begin{abstract}
About the author
Marié-Luce Muller is a consulting CI analyst with IBIS Business and Information Services (Pty) Ltd, a leading Pretoria-based CI consultancy. She has a distinguished career in CI. Her primary experience lies in assisting companies in honing their CI capabilities. She also performs tracking and scanning activities on behalf of companies. Marié-Luce has published many articles on competitive intelligence (CEO Magazine, Finance Week, Business Week, Beeld, Die Burger and the South African Journal of Business Management), including an article on South Africa as an emerging CI player, which was published in an international publication of the Society of Competitive Intelligence Professionals (SCIP). She has also published a series of booklets on CI (Nuts and Bolts business series, published by Knowledge Resources) and is a member of a research team participating in an international study of CI practices among exporting companies. Previously, she was involved in research into the status of CI practices in South Africa. A member of SCIP, she holds a postgraduate degree from the University of Stellenbosch.
\end{abstract}

\title{
Disclaimer
}

Articles published in SAJIM are the opinions of the authors and do not necessarily reflect the opinion of the Editor, Board, Publisher, Webmaster or the Rand Afrikaans University. The user hereby waives any claim he/she/they may have or acquire against the publisher, its suppliers, licensees and sub licensees and indemnifies all said persons from any claims, lawsuits, proceedings, costs, special, incidental, consequential or indirect damages, including damages for loss of profits, loss of business or downtime arising out of or relating to the user's use of the Website. 
ISSN 1560-683X

Published by InterWord Communications for Department of Information and Knowledge Management, University of Johannesburg 